\title{
Laser Synthesis of Iridium Nanospheres for Overall Water Splitting
}

\author{
Hai-Bin Wang ${ }^{1}{ }^{(0)}$, Jia-Qi Wang ${ }^{1}$, Neli Mintcheva ${ }^{2,3}{ }^{\circledR}$, Min Wang ${ }^{1}$, Shuang Li $^{1}$, Jing Mao ${ }^{1}$, \\ Hui Liu ${ }^{1}\left(\mathbb{D}\right.$, Cun-Ku Dong ${ }^{1, *}$, Sergei A. Kulinich ${ }^{2,4, *}$ (D) and Xi-Wen Du ${ }^{1, *}$ \\ 1 Institute of New-Energy Materials, School of Materials Science and Engineering, Tianjin University, \\ Tianjin 300350, China; hibwang@tju.edu.cn (H.-B.W.); jq_wang@tju.edu.cn (J.-Q.W.); \\ wangmin6029@126.com (M.W.); 15632301425@163.com (S.L.); maojing@tju.edu.cn (J.M.); \\ hui_liu@tju.edu.cn (H.L.) \\ 2 Research Institute of Science and Technology, Tokai University, Hiratsuka, Kanagawa 259-1292, Japan; \\ nnmintcheva@mgu.bg \\ 3 Department of Chemistry, University of Mining and Geology, Sofia 1700, Bulgaria \\ 4 Department of Mechanical Engineering, Tokai University, Hiratsuka, Kanagawa 259-1292, Japan \\ * Correspondence: ckdong@tju.edu.cn (C.-K.D.); skulinich@tokai-u.jp (S.A.K.); xwdu@tju.edu.cn (X.-W.D.)
}

Received: 12 August 2019; Accepted: 15 September 2019; Published: 18 September 2019

\begin{abstract}
Engineering surface structure of catalysts is an efficient way towards high catalytic performance. Here, we report on the synthesis of regular iridium nanospheres (Ir NSs), with abundant atomic steps prepared by a laser ablation technique. Atomic steps, consisting of one-atom level covering the surface of such Ir NSs, were observed by aberration-corrected high-angle annular dark-field scanning transmission electron microscopy (HAADF-STEM). The prepared Ir NSs exhibited remarkably enhanced activity both for oxygen evolution reaction (OER) and hydrogen evolution reaction (HER) in acidic medium. As a bifunctional catalyst for overall water splitting, they achieved a cell voltage of $1.535 \mathrm{~V} @ 10 \mathrm{~mA} / \mathrm{cm}^{2}$, which is much lower than that $\mathrm{Pt} / \mathrm{C}$-Ir/C couple (1.630 V@ $\left.10 \mathrm{~mA} / \mathrm{cm}^{2}\right)$.
\end{abstract}

Keywords: laser ablated nanoparticles; Ir nanoparticles; bifunctional catalyst; overall water splitting

\section{Introduction}

Electrochemical water splitting has been known as an efficient strategy for the storage of intermittent electrical energy, via hydrogen evolution reaction (HER) and oxygen evolution reaction (OER) [1,2]. The main concern for this technology is to design efficient HER and OER electrocatalysts, especially for acidic media [3-5]. As a noble metal, iridium shows a high potential for water splitting [6-9]. Nevertheless, its performance has barely been satisfactory thus far, due to the inappropriate adsorption of OER and HER intermediates [10-12]. Hence, many efforts, e.g., those based on particle size reduction $[13,14]$, use of composites [15,16], and alloying [17-20], have been made to improve and optimize Ir catalysts.

Surface structure of catalysts can make a significant impact on the adsorption of intermediates, thus efficiently influencing catalytic properties. For instance, atomic steps on catalyst surfaces were reported to lead to unsaturated catalytic sites [21,22], and exhibit great advantages in CO oxidation [23], ethanol oxidation [24], oxygen reduction [25], and $\mathrm{CO}_{2}$ reduction [26]. Nevertheless, common wet-chemistry routes usually give rise to Ir catalysts with flat facets resulted from their equilibrium growth, which severely prevents the formation of atomic steps [20,27-29].

Herein, we employed a physical method, pulsed laser ablation in liquid (PLAL) [30-42] to produce Ir nanospheres (Ir NSs) enriched with surface atomic steps. This method is known as an 
efficient approach for preparation of various metallic nanoparticles [30,31,40-42], including those for electrocatalysis [40-42]. The as-prepared catalyst exhibits excellent OER and HER activities superior to those of commercial $\mathrm{Ir} / \mathrm{C}$ and $\mathrm{Pt} / \mathrm{C}$ electrodes in acidic medium, indicating that atomic steps on particle surface are advantageous for catalytic performance. After characterization, the as-prepared Ir NSs were employed as a bifunctional catalyst for overall water splitting, achieving a very low cell voltage of $1.535 \mathrm{~V} @ 10 \mathrm{~mA} / \mathrm{cm}^{2}$ in $0.5 \mathrm{M} \mathrm{H}_{2} \mathrm{SO}_{4}$, which is about $100 \mathrm{mV}$ lower than that for the $\mathrm{Pt} / \mathrm{C}$-Ir/C couple $\left(1.630 \mathrm{~V} @ 10 \mathrm{~mA} / \mathrm{cm}^{2}\right)$. Our work proves that PLAL is a promising approach to produce non-conventional surface structures, while the obtained results pave a new way towards highly effective noble-metal catalysts for water splitting.

\section{Materials and Methods}

Synthesis of Ir NSs. Ir NSs were produced by laser ablation of an Ir target immersed in deionized water. Nd:YAG laser (Dawa-350, Beamtech, Beijing, China) was operated at wavelength $1064 \mathrm{~nm}$, pulse width $7 \mathrm{~ns}$, single-pulse energy $250 \mathrm{~mJ}$, and frequency $15 \mathrm{~Hz}$. More details about this preparation approach can be found elsewhere [30-35]. More specifically, an Ir plate $(30 \mathrm{~mm} \times 30 \mathrm{~mm} \times 3 \mathrm{~mm}$, $99.99 \%$ ) was first polished by sandpaper to remove the surface oxide layer, followed by rinsing with deionized water. Next, the target was immersed in deionized water with its upper surface $20 \mathrm{~mm}$ below the water level, and then ablated by the above mentioned pulsed laser for $30 \mathrm{~min}$ at room temperature. The as-obtained colloid was mixed with carbon black at a mass ratio $\operatorname{Ir} / \mathrm{C}$ of 1:4. The mixture was first ultrasonicated and then centrifuged. Finally, the precipitate was dried in a lyophilizer to get the final product, which was used as electrode.

Preparation of commercial Ir/C. The commercial Ir nanomaterial (Hesen, 99.99\%) was mixed with carbon black at the same mass ratio, $\operatorname{Ir} / \mathrm{C}=1: 4$. The mixture was also first ultrasonicated and then centrifuged. Finally, the precipitate was dried in a lyophilizer to get the final product, which was used as electrode.

Characterizations of catalysts. Transmission electron microscopy (TEM) analysis was carried out in an FEI Technai G2 F20 (JEOL, Tokyo, Japan) tool equipped with a field-emission gun, and with energy-dispersive X-ray spectroscopy (EDS) module. High-angle annular dark-field scanning transmission electron microscopy (HAADF-STEM) images were obtained by a JEOL ARM-200F instrument (JEOL, Tokyo, Japan), equipped with a cold-field emission gun and a Cs corrector (CEOS) for probing lenses, which was operated at a voltage of $200 \mathrm{kV}$. X-ray diffraction (XRD) patterns were measured on a Bruker D8 Advance diffractometer (Bruker, Karlsruhe, Germany) with Cu K $\alpha$ radiation and a Lynx Eye detector (Bruker, Karlsruhe, Germany). X-ray photoelectron spectroscopy (XPS) analysis was performed using a PHI Quantum 2000 scanning ESCA Microprobe spectrometer (Physical Electronics Company, Austin, TX, USA). Raman spectra were obtained using a DXR Microscope Raman spectrophotometer (Renishaw, London, UK) with laser excitation of $532 \mathrm{~nm}$.

Electrochemical measurements. A CHI660E electrochemical workstation (Chenhua, Shanghai, China) was used for testing the HER and OER performance of different catalysts. For electrochemical tests, $3 \mathrm{mg}$ of catalyst were dispersed into $0.6 \mathrm{~mL}$ of deionized water, isopropanol, and $5 \mathrm{wt} \% \mathrm{Nafion}$ mixture used as solvent (volume ratio: $400 \mu \mathrm{L}: 170 \mu \mathrm{L}: 30 \mu \mathrm{L}$ ) via sonication to prepare an ink with catalyst. Next, $3.6 \mu \mathrm{L}$ of the ink was loaded onto carbon fiber paper with a fixed area of $0.3 \times 0.3 \mathrm{~cm}^{2}$, which was used as the working electrode with a catalyst loading of $0.2 \mathrm{mg} / \mathrm{cm}^{2}$. Electrolysis experiments were carried out in a standard three-electrode system with $\mathrm{O}_{2}(\mathrm{OER}) / \mathrm{N}_{2}(\mathrm{HER})$-saturated $0.5 \mathrm{M} \mathrm{H}_{2} \mathrm{SO}_{4}$. A measurement system was composed of a $\mathrm{CHI} 600 \mathrm{E}$ electrochemistry workstation, working electrode with catalyst loaded on carbon fiber paper, counter electrode (carbon rod), and reference electrode (saturated calomel electrode $\mathrm{Hg} / \mathrm{HgCl}_{2} / \mathrm{KCl}$ ). The applied potentials were converted with respect to RHE:

$$
E_{R H E}(V)=E_{S C E}+0.242+0.0591 \times p H_{\text {electrolyte }}
$$

Before recording, the potential of each catalyst was scanned at $50 \mathrm{mV} / \mathrm{s}$ between 0 and $1.4 \mathrm{~V}$ (vs. RHE) for OER and between 0 and $-0.2 \mathrm{~V}$ (vs. RHE) for HER, until a stable cyclic voltammogram (CV) 
was obtained. Afterwards, linear sweeping voltammogram (LSV) curves were recorded at a scan rate of $5 \mathrm{mV} / \mathrm{s}$, and Tafel slopes were obtained by plotting overpotential against $\log (J)$ from the LSV curves. EIS profiles were recorded under $1.53 \mathrm{~V}$ (vs. RHE) for OER in a frequency range from 0.1 to $10^{5} \mathrm{~Hz}$. The electrochemical surface area (ECSA) was measured in the potential window of 1.042-1.142 V (vs. RHE) for OER, using different scan rates of 5, 10, 15, 20, 25, and $30 \mathrm{mV} / \mathrm{s}$. As for the electrochemical measurements of the overall water splitting, we acquired the LSV between 1.0 and $1.8 \mathrm{~V}$ at a scan rate of $5 \mathrm{mV} / \mathrm{s}$. All OER LSV curves were corrected for $i R$ drop at $95 \%$.

\section{Results and Discussion}

The preparation of Ir NSs is schematically illustrated in Figure 1a. The Ir metal target immersed in deionized water was ablated by a nanosecond pulsed laser to form vapor and/or molten nanodroplets, which then were quenched by the surrounding liquid medium, resulting in Ir NSs with inerratic cambered surface containing abundant atomic steps. The XRD pattern of as-produced Ir NSs (Figure 1b) shows a typical face-centered cubic structure, indexed as metallic Ir phase (PDF \#06-0598). The high purity of Ir nanoparticles is confirmed by the EDS spectrum in Figure 1c and elemental mapping (Figure S1). The high-resolution TEM (HR-TEM) image of a single Ir particle exhibits a regular spherical shape and single crystal structure, with a lattice spacing of $0.222 \mathrm{~nm}$ corresponding to the (111) plane of metallic Ir (Figure 1d). The low-magnification TEM image (inset in Figure 1d) reveals that the sample contains Ir NSs with a wide range of sizes from 5 to $40 \mathrm{~nm}$, with an average size being $21.5 \mathrm{~nm}$ (Figure S2). More intriguingly, the HAADF-STEM image presented in Figure 1e displays several atomic steps on the particle surface, all with a height of a single atomic layer.

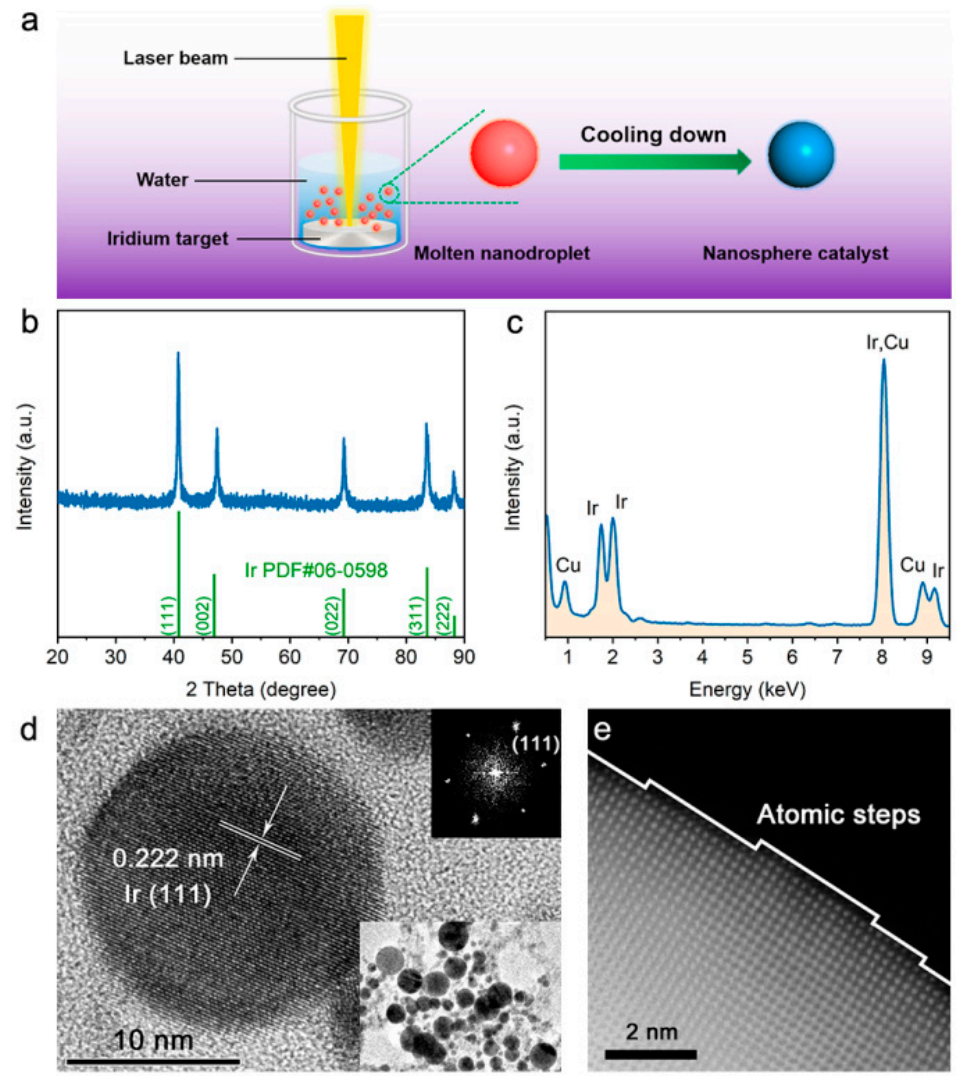

Figure 1. Preparation and characterization of Ir NSs. (a) Schematic illustration of preparation procedure involving PLAL. (b) XRD pattern and (c) EDS spectrum of as-prepared Ir NSs (the Cu signals are from Cu grid used as substrate). (d) HRTEM image of a single Ir NS, corresponding FFT (Fast Fourier Transform) pattern and low-magnification TEM image of Ir NSs are given as insets. (e) HRHAADF-STEM image of the surface of a single Ir NS. 
Next, upon preparing electrodes, we investigated the OER properties of the Ir NSs in $\mathrm{O}_{2}$-saturated $0.5 \mathrm{M} \mathrm{H}_{2} \mathrm{SO}_{4}$ solution, with commercial $\mathrm{Ir} / \mathrm{C}$ and $\mathrm{Pt} / \mathrm{C}$ electrodes as references. LSV profiles demonstrated that the Ir NSs exhibited the lowest overpotential of $266 \mathrm{mV}$ to achieve a current density of $10 \mathrm{~mA} / \mathrm{cm}^{2}$, which is much better than those of the $\mathrm{Ir} / \mathrm{C}(333 \mathrm{mV}), \mathrm{Pt} / \mathrm{C}(547 \mathrm{mV})$, and other OER electrocatalysts (Figure 2a and Table S1). The Tafel slope of the Ir NSs was determined as $58.7 \mathrm{mV} /$ decade (Figure $2 \mathrm{~b}$ ), which is notably lower than those of the $\mathrm{Ir} / \mathrm{C}(89.1 \mathrm{mV} /$ decade $)$ and $\mathrm{Pt} / \mathrm{C}$ (347.7 mV/decade) electrodes, indicating the fast kinetics of the laser-prepared catalyst based on Ir NSs.
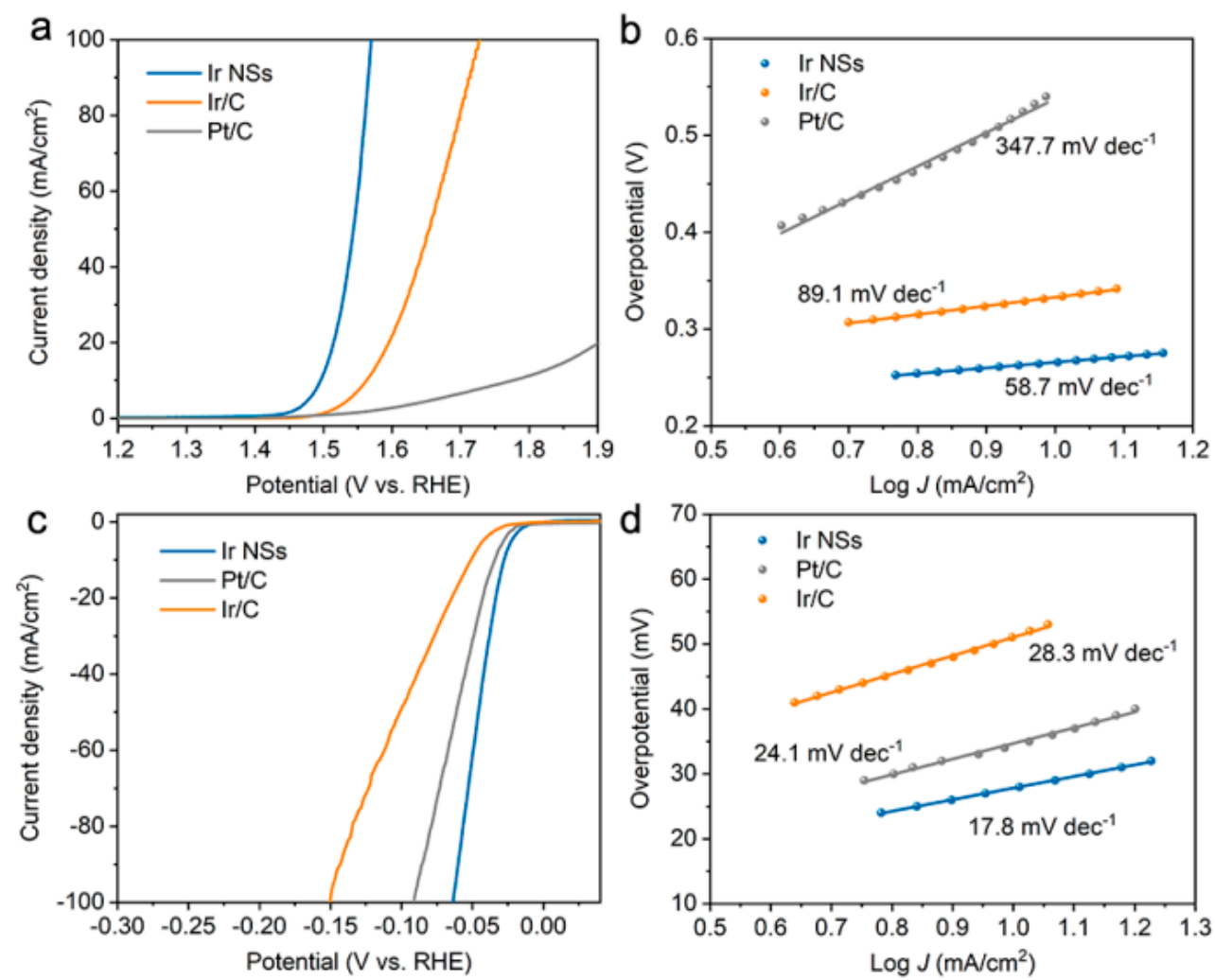

Figure 2. Electrocatalytic OER and HER performance of Ir NSs (blue curves), commercial Ir/C (orange curves), and commercial Pt/C (grey curves). (a) OER LSV curves in aqueous solution of $0.5 \mathrm{M} \mathrm{H}_{2} \mathrm{SO}_{4}$ purged with $\mathrm{O}_{2}$. (b) Tafel plots for OER. (c) HER LSV curves in aqueous solution of $0.5 \mathrm{M} \mathrm{H}_{2} \mathrm{SO}_{4}$ purged with $\mathrm{N}_{2}$. (d) Tafel plots for HER.

Meanwhile, the ECSA values were determined by integrating the hydrogen adsorption charge on the cyclic voltammogram (CV). As shown in Figure 3c, the value obtained for Ir NSs $\left(6.81 \mathrm{mF} / \mathrm{cm}^{2}\right)$ is higher than that of $\mathrm{Ir} / \mathrm{C}\left(5.16 \mathrm{mF} / \mathrm{cm}^{2}\right)$, implying more active sites in the laser-produced Ir NSs in comparison with their commercial counterparts. The intrinsic activities of Ir NSs and Ir/C were evaluated by normalizing the current densities to the ECSA (defined as specific activity), as seen in Figure 4a. The Ir NSs were found to show significantly enhanced specific activity, compared with the commercial Ir/C. At a potential of $1.53 \mathrm{~V}$ vs. RHE, the PLAL-generated Ir NSs achieved more than 6-fold improvement in specific activity over commercial Ir/C (see Figure $4 \mathrm{~b}$ ). The results of electrochemical impedance spectroscopy (EIS) presented in Figure S3 show that the charge transfer resistance of laser-produced Ir NSs $(69.3 \Omega)$ is significantly lower than that of commercial $\operatorname{Ir} / \mathrm{C}(115.4 \Omega)$, suggesting a faster electron transfer between the Ir NSs and electrolyte. Importantly, the durability of Ir NSs was also found to be very good. As shown in Figure 5a, their OER activity barely changed after 1000 cyclic voltammetry scans. Long-term stability was assessed at a current density of $10 \mathrm{~mA} / \mathrm{cm}^{2}$, and the electrode based on Ir NSs retained a steady OER overpotential over a period of $10 \mathrm{~h}$, thus being 
superior to commercial Ir/C (see Figure $5 b$ ). In addition, the Ir NSs were found to maintain their spherical morphology after the OER stability test (see Figure S4).
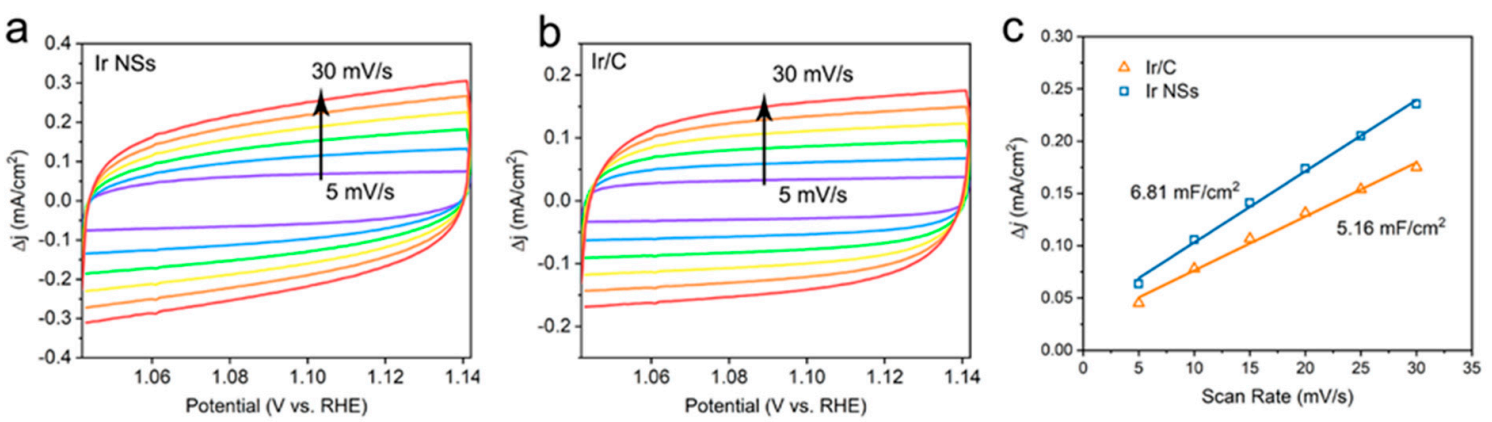

Figure 3. CV curves at different scan rates $(5,10,15,20,25$, and $30 \mathrm{mV} / \mathrm{s}$ ) for (a) laser-produced Ir NSs and (b) commercial Ir/C in the potential window of 1.042-1.142 V (vs. RHE) for OER. (c) Plots of current density versus scan rate to determine double layer capacitance (Cdl) for Ir NSs (blue) and Ir/C (orange) catalysts.
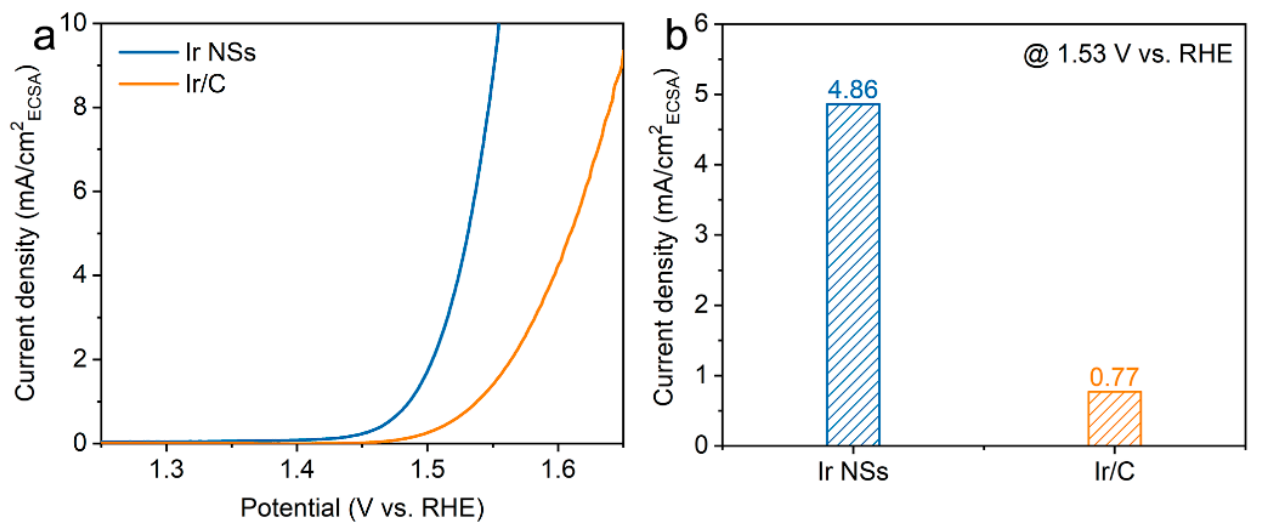

Figure 4. (a) ECSA-corrected polarization curves for Ir NSs (blue curve) and Ir/C (orange curve). (b) OER current normalized to the ECSA (specific activity) at a potential of $1.53 \mathrm{~V}$ (vs. RHE).

a

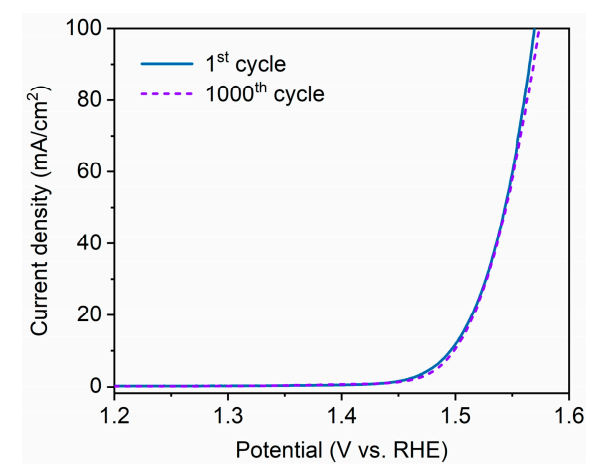

b

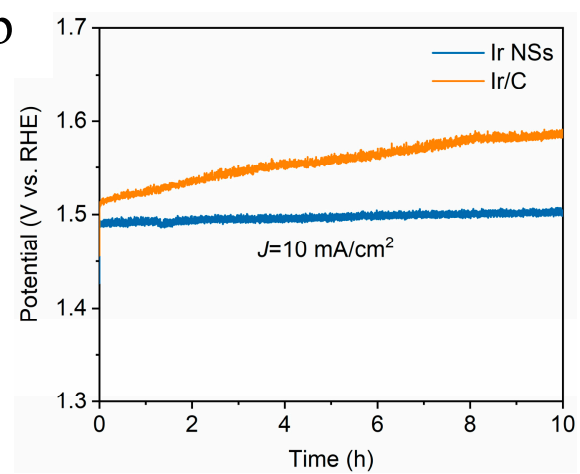

Figure 5. (a) LSV curves for Ir NSs before and after $1000 \mathrm{CV}$ scans for OER test in acidic medium. (b) Chronopotentiometry curves of Ir NSs (blue) and Ir/C (orange curve) for OER test at a constant current density of $10 \mathrm{~mA} / \mathrm{cm}^{2}$.

The HER activity of the Ir NSs was examined in $0.5 \mathrm{M} \mathrm{H}_{2} \mathrm{SO}_{4}$ solution purged with $\mathrm{N}_{2}$. As shown in Figure 2c,d, the Ir NSs merely need an overpotential of $28 \mathrm{mV}$ to achieve a current density of $10 \mathrm{~mA} / \mathrm{cm}^{2}$ with a Tafel slope of $17.8 \mathrm{mV} /$ decade, which is significantly lower than similar values for the commercial products $\mathrm{Pt} / \mathrm{C}$ ( $34 \mathrm{mV}$ and $24.1 \mathrm{mV} /$ decade) and $\mathrm{Ir} / \mathrm{C}(51 \mathrm{mV}$ and $28.3 \mathrm{mV} /$ decade). Moreover, the laser-prepared Ir NSs exhibit superior durability towards HER (see Figure 6a). During continuous 
electrolysis for $10 \mathrm{~h}$ at a constant current density of $10 \mathrm{~mA} / \mathrm{cm}^{2}$, they demonstrated a negligible degree of degradation, whereas commercial $\mathrm{Pt} / \mathrm{C}$ electrode exhibits quite poor stability (see Figure $6 \mathrm{~b}$ ). At the same time, TEM investigations indicated that the morphology of Ir NSs did not change after $10 \mathrm{~h}$ of durability testing, thus also confirming good stability of the new catalyst (see Figure S5).
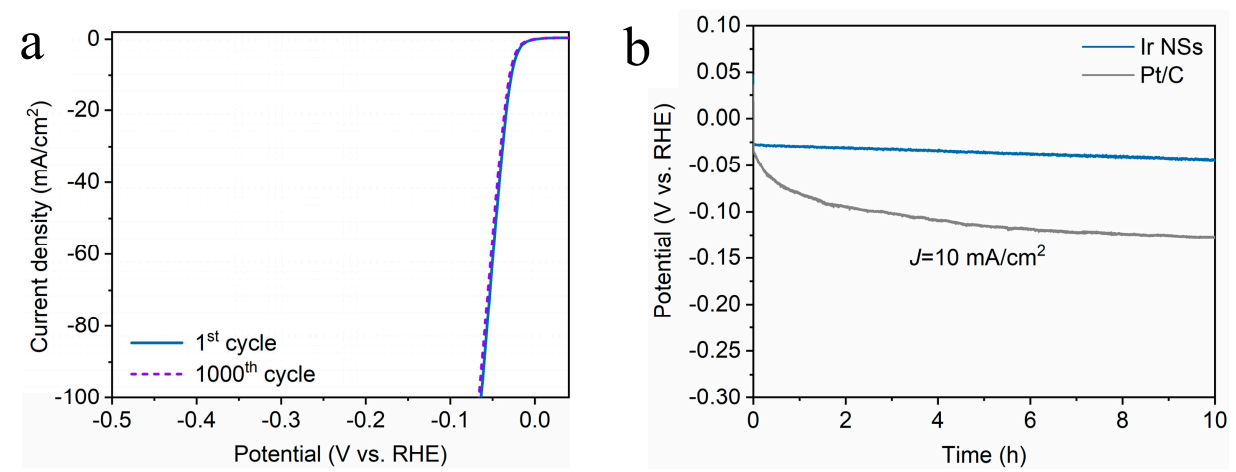

Figure 6. (a) LSV curves of Ir NSs before and after $1000 \mathrm{CV}$ scans for HER test under basic conditions. (b) Chronopotentiometry curves of Ir NSs (blue) and Pt/C (gray curve) during HER test at a constant current density of $10 \mathrm{~mA} / \mathrm{cm}^{2}$.

To understand the origin of high performance of the newly developed catalyst based on PLAL-generated Ir NSs, we carried out XPS analysis on both Ir NSs and commercial Ir/C before and after OER tests. The results indicate that after OER test, the Ir NSs were oxidized into $\mathrm{IrO}_{\mathrm{x}}$ (see Figure 7a), while the nanoparticles in commercial $\mathrm{Ir} / \mathrm{C}$ product kept their metallic state to a larger degree (see Figure $7 \mathrm{~b}$ ). This finding is further confirmed by Raman results and XPS O 1s spectra (presented in Figures S6 and S7). The observed oxidation of laser-produced Ir NSs can be rationalized as follows. In comparison with the commercial Ir/C particles shown in Figure S8 (with flat facets), the laser-generated NSs are much more chemically active because of numerous atomic steps with lower coordination numbers on their surface [21-24]. That is why they are easier to be electrochemically oxidized (see Figure 7c and Figure S9a). As well known, electrochemically induced $\mathrm{IrO}_{\mathrm{x}}$ is much more active for OER compared with metallic Ir $[4,12,16]$, which is why much better OER performance was observed for laser-generated Ir NSs. In addition, the surface steps should also favor the HER activity of the Ir NSs. For metallic Ir catalysts, their weak adsorption energy for $\mathrm{H}^{+}$is known to restrict their HER performance $[10,11]$. Importantly, the atoms at surface steps possess lower coordination numbers [21-24], which can improve the adsorption energy of $\mathrm{H}^{+}$and thus reduce the overpotential of HER (see Figure $7 d$ and Figure S9b). Therefore, the high HER performance of PLAL-produced Ir NSs could also be attributed to the plentiful surface atomic steps.

Given the excellent OER and HER activities demonstrated by the novel catalyst in acidic solution, we employed the Ir NSs as a bifunctional catalyst for overall water splitting in aqueous solution of $0.5 \mathrm{M} \mathrm{H}_{2} \mathrm{SO}_{4}$ (see Figure 8a). As shown in Figure 8b, the Ir NSs exhibited superior activity, with a cell voltage of $1.535 \mathrm{~V}$ at a current density of $10 \mathrm{~mA} / \mathrm{cm}^{2}$. For comparison, the commercial $\mathrm{Ir} / \mathrm{C}-\mathrm{Pt} / \mathrm{C}$ couple required a significantly higher cell voltage of $1.630 \mathrm{~V}$ to deliver the same current density, which is about $100 \mathrm{mV}$ higher than that for the Ir NSs (Figure 8b). As seen in Figure 8c, the performance of the novel Ir NSs is among the top values achieved by bifunctional catalysts working in acidic solution (also see Tables S1-S3 in supporting information). In addition, the Ir NSs also exhibited very high durability, as the applied voltage for $10 \mathrm{~mA} / \mathrm{cm}^{2}$ merely increases by $60 \mathrm{mV}$ after $20 \mathrm{~h}$ of non-stop operation. This was only $1 / 6$ of that for the commercial $\mathrm{Pt} / \mathrm{C}-\mathrm{Ir} / \mathrm{C}$ couple $(370 \mathrm{mV}$ after $10 \mathrm{~h}$ ) (see Figure $8 \mathrm{~d})$. The molar ratio of released gases $\left(\mathrm{H}_{2}\right.$ and $\left.\mathrm{O}_{2}\right)$ was measured and shown in Figure $\mathrm{S} 10$, suggesting the Faraday efficiency of the novel catalyst was nearly $100 \%$ at $100 \mathrm{~mA} / \mathrm{cm}^{2}$. Remarkably, a solar cell with an open-circuit voltage of $1.5 \mathrm{~V}$ could drive the water splitting device with obvious and stable gas formation, as well seen in Figure 8d (inset) and Figure S11. Such a solar-power assisted water splitting device can be potentially applied in distributed energy storage technologies. 
a

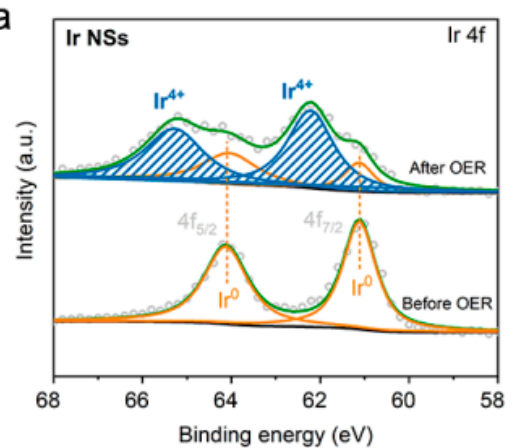

C

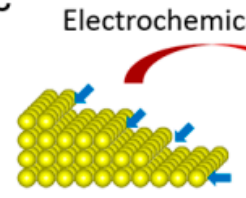

Easy to oxidation b

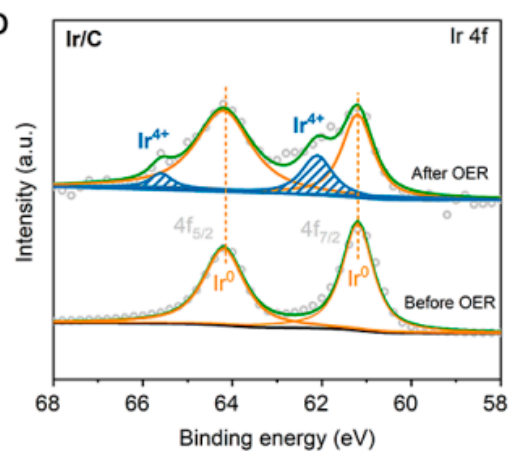

d

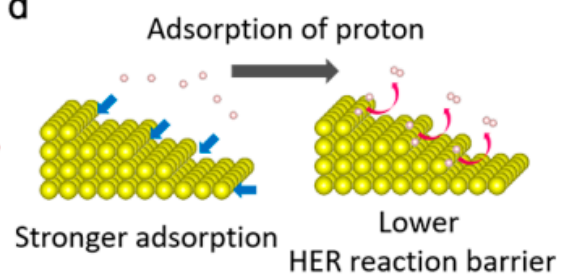

Stepped surface

Stepped surface

Figure 7. Narrow-scan XPS Ir 4f spectra for (a) Ir NSs and (b) commercial Ir/C before (bottom) and after (top) the OER test. Proposed mechanisms of (c) OER and (d) HER on stepped surface of Ir NSs. Blue arrows indicate atomic steps, while green and pink arrows indicate the evolution of oxygen and hydrogen, respectively.
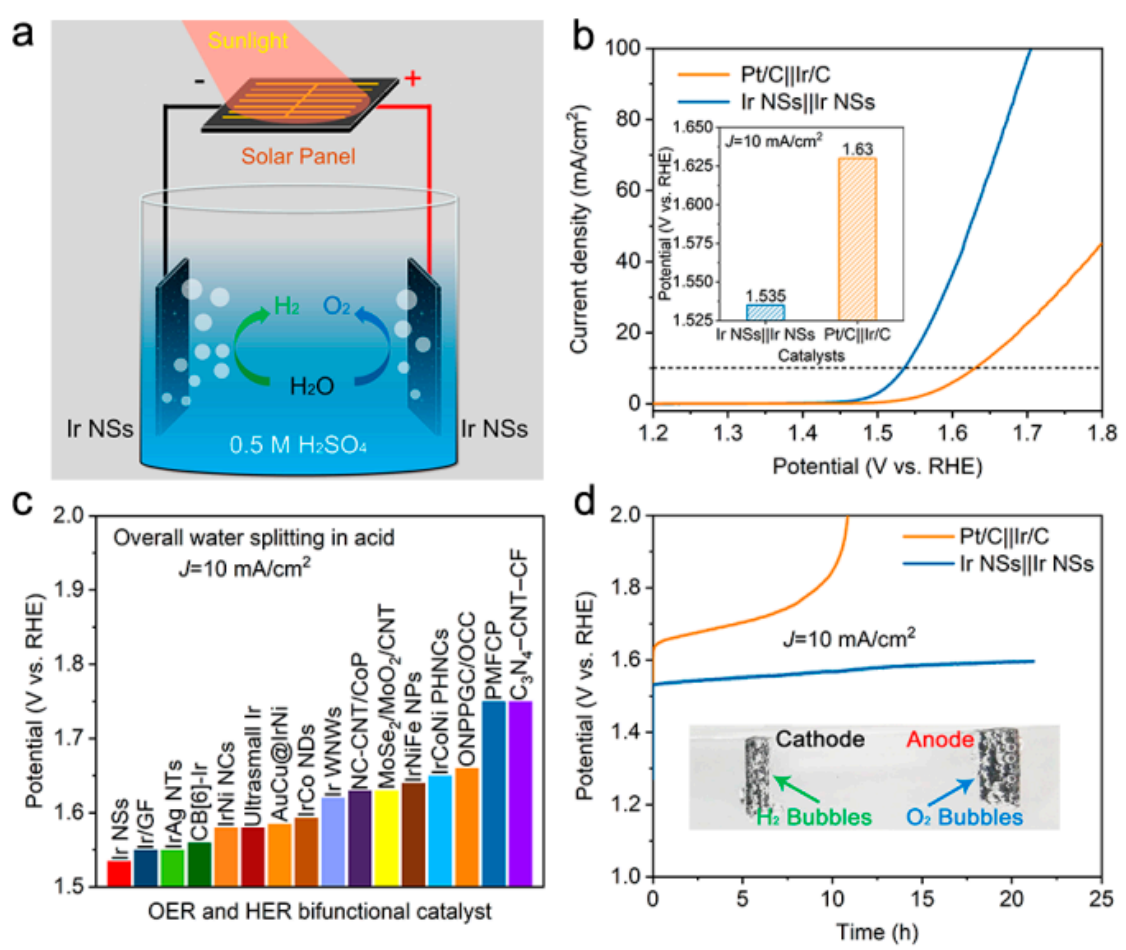

Figure 8. Performance of laser-generated Ir NSs as catalyst for overall water splitting in acidic medium. (a) Schematic image of an electrolyzer driven by a solar cell, with Ir NSs as both anode and cathode in $0.5 \mathrm{M} \mathrm{H}_{2} \mathrm{SO}_{4}$ solution. (b) LSV curves of Ir NSs and commercial Pt/C-Ir/C couple in aqueous $0.5 \mathrm{M}$ $\mathrm{H}_{2} \mathrm{SO}_{4}$ purged with $\mathrm{N}_{2}$ for overall water splitting. (c) Comparison of required voltage at a current density of $10 \mathrm{~mA} / \mathrm{cm}^{2}$ for Ir NSs with other bifunctional catalysts reported in the literature (exact values can be seen in Tables S1-S3). (d) Chronopotentiometry test of Ir NSs in comparison with commercial $\mathrm{Pt} / \mathrm{C}$-Ir/C couple in aqueous $0.5 \mathrm{M} \mathrm{H}_{2} \mathrm{SO}_{4}$ at a current density of $10 \mathrm{~mA} / \mathrm{cm}^{2}$. Inset shows an optical image with production of $\mathrm{H}_{2}$ and $\mathrm{O}_{2}$ on corresponding electrodes. 


\section{Conclusions}

In conclusion, using the laser ablation in water, we prepared Ir nanoparticles with numerous atomic steps on their surface. After preparation, the Ir nanoparticles were tested as catalysts for water splitting. The unique surface morphology of the prepared nanoparticles was demonstrated to facilitate their surface oxidation during OER process, and enhance the adsorption of HER intermediate. As a result, the electrode based on the new Ir nanocatalyst demonstrated lower OER and HER overpotentials simultaneously. As a bifunctional catalyst for overall water splitting in acidic medium, the laser-produced Ir nanomaterial provided a current density of $10 \mathrm{~mA} / \mathrm{cm}^{2}$ at a low voltage of $1.535 \mathrm{~V}$ with a long-term stability. The present work demonstrates that laser ablation in liquid phase is a promising technique to prepare metallic nanomaterials with surface atomic steps and improved catalytic performance. This strategy is believed to be capable of preparing other materials and producing novel catalysts for energy conversion and other related applications.

Supplementary Materials: The following are available online at http://www.mdpi.com/1996-1944/12/18/3028/s1, Figure S1: HAADF-STEM image and the corresponding EDS mapping of Ir NSs showing elemental distribution of Ir (blue), Figure S2: Size distribution of Ir NSs. The average size is $21.5 \mathrm{~nm}$, Figure S3: EIS of Ir NSs and Ir/C recorded at a potential of $1.53 \mathrm{~V}$ (vs. RHE), Figure S4: TEM (a) and HRTEM (b) images of the Ir NSs after OER test, Figure S5: TEM (a) and HRTEM (b) images of Ir NSs after HER test, Figure S6: Raman shift spectra of Ir NSs and Ir/C before (a) and after (b) OER test, Figure S7: XPS O 1s spectra of Ir NSs (a) and commercial Ir/C (b) before and after OER test, Figure S8: TEM (a) and HRTEM $(b, c)$ images of commercial Ir/C, Figure S9: Proposed mechanism of OER (a) and HER (b) in flat surface of Ir/C, Figure S10: Faraday efficiency of the corresponding gas products $\left(\mathrm{O}_{2}\right.$ and $\left.\mathrm{H}_{2}\right)$ at the current density of $100 \mathrm{~mA} / \mathrm{cm}^{2}$, Figure S11: Photograph of overall water splitting driven by a 1.5 V solar cell, Table S1: Comparison of OER activity for different electrocatalysts in acidic electrolytes, Table S2: Comparison of HER activity for different electrocatalysts in acidic electrolytes, Table S3: Comparison of overall water splitting activity for different electrocatalysts in acidic electrolytes.

Author Contributions: H.-B.W., J.-Q.W., and X.-W.D. designed the work; H.-B.W., J.-Q.W., S.L., J.M., and M.W. carried out the experiment; J.-Q.W., H.L., C.-K.D., S.L., and N.M. conducted most of analyses. J.-Q.W., S.L., C.-K.D., N.M., S.A.K., and X.-W.D. wrote the manuscript. All authors discussed the results and helped prepare the manuscript.

Funding: This work was supported by the Natural Science Foundation of China (Nos. 51871160, 51671141, and 51471115)

Conflicts of Interest: The authors declare no conflicts of interest.

\section{References}

1. Hunter, B.M.; Gray, H.B.; Müller, A.M. Earth-abundant heterogeneous water oxidation catalysts. Chem. Rev. 2016, 116, 14120-14136. [CrossRef] [PubMed]

2. Wang, P.T.; Zhang, X.; Zhang, J.; Wan, S.; Guo, S.J.; Lu, G.; Yao, J.L.; Huang, X.Q. Precise tuning in platinum-nickel/nickel sulfide interface nanowires for synergistic hydrogen evolution catalysis. Nat. Commun. 2017, 8, 14580. [CrossRef] [PubMed]

3. Wang, J.H.; Cui, W.; Liu, Q.; Xing, Z.C.; Asiri, A.M.; Sun, X.P. Recent Progress in cobalt-based heterogeneous catalysts for electrochemical water splitting. Adv. Mater. 2016, 28, 215-230. [CrossRef] [PubMed]

4. Kwon, T.; Hwang, X.; Sa, Y.J.; Park, J.; Baik, H.; Joo, S.H.; Lee, K. Cobalt assisted synthesis of IrCu hollow octahedral nanocages as highly active electrocatalysts toward oxygen evolution reaction. Adv. Funct. Mater. 2017, 27, 1604688. [CrossRef]

5. Zhang, H.W.; Shen, P.K. Recent development of polymer electrolyte membranes for fuel cells. Chem. Rev. 2012, 112, 2780-2832. [CrossRef] [PubMed]

6. Oh, H.S.; Nong, H.N.; Reier, T.; Bergmann, A.; Gliech, M.; Araujo, J.F.; Willinger, E.; Schlögl, R.; Teschner, D.; Strasser, P. Electrochemical catalyst-support effects and their stabilizing role for $\mathrm{IrO}_{\mathrm{x}}$ nanoparticle catalysts during the oxygen evolution reaction. J. Am. Chem. Soc. 2016, 138, 12552-12563. [CrossRef] [PubMed]

7. Fu, L.H.; Yang, F.L.; Cheng, G.Z.; Luo, W. Ultrathin Ir nanowires as high-performance electrocatalysts for efficient water splitting in acidic media. Nanoscale 2018, 10, 1892-1897. [CrossRef]

8. Park, J.; Choi, S.; Oh, A.; Jin, H.; Joo, J.; Baik, H.; Lee, K. Hemi-core@frame AuCu@IrNi nanocrystals as active and durable bifunctional catalysts for the water splitting reaction in acidic media. Nanoscale Horiz. 2019, 4, 727-734. [CrossRef] 
9. Li, S.; Xi, C.; Jin, Y.; Wu, D.Y.; Wang, J.Q.; Liu, T.; Wang, H.B.; Dong, C.; Liu, H.; Kulinich, S.A.; et al. Ir-O-V catalytic group in Ir-doped $\mathrm{NiV}(\mathrm{OH})_{2}$ for overall water splitting. ACS Energy Lett. 2019, 4, 1823-1829. [CrossRef]

10. Seh, Z.W.; Kibsgaard, J.; Dickens, C.F.; Chorkendorff, I.; Nørskov, J.K.; Jaramillo, T.F. Combining theory and experiment in electrocatalysis: Insights into materials design. Science 2017, 355, 146. [CrossRef]

11. Lv, F.; Feng, J.R.; Wang, K.; Dou, Z.P.; Zhang, W.Y.; Zhou, J.H.; Yang, C.; Luo, M.C.; Yang, Y.; Li, Y.J.; et al. Iridium-tungsten alloy nanodendrites as $\mathrm{pH}$-universal water-splitting electrocatalysts. ACS Cent. Sci. 2018, 4, 1244-1252. [CrossRef] [PubMed]

12. Zhu, J.W.; Chen, Z.T.; Xie, M.H.; Lyu, Z.H.; Chi, M.F.; Mavrikakis, M.; Jin, W.Q.; Xia, Y.N. Iridium-based cubic nanocages with 1.1-nm-thick walls: A highly efficient and durable electrocatalyst for water oxidation in an acidic medium. Angew. Chem. Int. Ed. 2019, 58, 7244-7248. [CrossRef] [PubMed]

13. Fu, L.H.; Zeng, X.; Huang, C.Z.; Cai, P.; Cheng, G.Z.; Luo, W. Ultrasmall Ir nanoparticles for efficient acidic electrochemical water splitting. Inorg. Chem. Front. 2018, 5, 1121-1125. [CrossRef]

14. Shi, Q.R.; Zhu, C.Z.; Zhong, H.; Su, D.; Li, N.; Engelhard, M.H.; Xia, H.B.; Zhang, Q.; Feng, S.; Beckman, S.P.; et al. Nanovoid incorporated $\operatorname{Ir}_{\mathrm{x}} \mathrm{Cu}$ metallic aerogels for oxygen evolution reaction catalysis. ACS Energy Lett. 2018, 3, 2038-2044. [CrossRef]

15. Zhang, J.; Wang, G.; Liao, Z.Q.; Zhang, P.P.; Wang, F.X.; Zhuang, X.D.; Zschech, E.; Feng, X.L. Iridium nanoparticles anchored on 3D graphite foam as a bifunctionalelectrocatalyst for excellent overall water splitting in acidic solution. Nano Energy 2017, 40, 27-33. [CrossRef]

16. You, H.H.; Wu, D.S.; Chen, Z.N.; Sun, F.F.; Zhang, H.; Chen, Z.H.; Cao, M.N.; Zhuang, W.; Cao, R. Highly active and stable water splitting in acidic media using a bifunctional iridium/cucurbit[6]uril catalyst. ACS Energy Lett. 2019, 4, 1301-1307. [CrossRef]

17. Feng, J.R.; Lv, F.; Zhang, W.Y.; Li, P.H.; Wang, K.; Yang, C.; Wang, B.; Yang, Y.; Zhou, J.H.; Lin, F.; et al. Iridium-based multimetallic porous hollow nanocrystals for efficient overall-water-splitting catalysis. Adv. Mater. 2017, 29, 1703798. [CrossRef] [PubMed]

18. Shan, J.Q.; Ling, T.; Davey, K.; Zheng, Y.; Qiao, S.Z. Transition-metal-doped RuIr bifunctional nanocrystals for overall water splitting in acidic environments. Adv. Mater. 2019, 31, 1900510. [CrossRef] [PubMed]

19. Fu, L.H.; Cheng, G.Z.; Luo, W. Colloidal synthesis of monodisperse trimetallic IrNiFe nanoparticles as highly active bifunctional electrocatalysts for acidic overall water splitting. J. Mater. Chem. A 2017, 5, 24836-24841. [CrossRef]

20. Pi, Y.C.; Shao, Q.; Zhu, X.; Huang, X.Q. Dynamic structure evolution of composition segregated iridium-nickel rhombic dodecahedra toward efficient oxygen evolution electrocatalysis. ACS Nano 2018, 12, 7371-7379. [CrossRef] [PubMed]

21. Chen, X.B.; Wu, D.X.; Zou, L.F.; Yin, Q.Y.; Zhang, H.L.; Zakharov, D.N.; Stach, E.A.; Zhou, G.W. In situ atomic-scale observation of inhomogeneous oxide reduction. Chem. Commun. 2018, 54, 7342-7345. [CrossRef] [PubMed]

22. Liu, J.; Chen, B.; Ni, Z.Y.; Deng, Y.D.; Han, X.P.; Hu, W.B.; Zhong, C. Improving the electrocatalytic activity of Pt monolayer catalysts for electrooxidation of methanol, ethanol and ammmonia by tailoring the surface morphology of the supporting core. ChemElectroChem 2016, 3, 537-551. [CrossRef]

23. Lee, S.W.; Chen, S.; Sheng, W.C.; Yabuuchi, N.; Kim, Y.T.; Mitani, T.; Vescovo, E.; Shao-Horn, Y. Roles of surface steps on Pt nanoparticles in electro-oxidation of carbon monoxide and methanol. J. Am. Chem. Soc. 2009, 131, 15669-15677. [CrossRef] [PubMed]

24. Wei, L.; Fan, Y.J.; Wang, H.H.; Tian, N.; Zhou, Z.Y.; Sun, S.G. Electrochemically shape-controlled synthesis in deep eutectic solvents of Pt nanoflowers with enhanced activity for ethanol oxidation. Electrochim. Acta 2012, 76, 468-474. [CrossRef]

25. Sun, Y.J.; Zhang, X.; Luo, M.C.; Chen, X.; Wang, L.; Li, Y.J.; Li, M.Q.; Qin, Y.N.; Li, C.J.; Xu, N.Y.; et al. Ultrathin PtPd-based nanorings with abundant step atoms enhance oxygen catalysis. Adv. Mater. 2018, 30, 1802136. [CrossRef] [PubMed]

26. Lee, H.E.; Yang, K.D.; Yoon, S.M.; Ahn, H.Y.; Lee, Y.Y.; Chang, H.; Jeong, D.H.; Lee, Y.S.; Kim, M.Y.; Nam, K.T. Concave rhombic dodecahedral Au nanocatalyst with multiple high-index facets for $\mathrm{CO}_{2}$ reduction. ACS Nano 2015, 9, 8384-8393. [CrossRef] [PubMed] 
27. Pi, Y.C.; Guo, J.; Shao, Q.; Huang, X.Q. Highly efficient acidic oxygen evolution electrocatalysis enabled by porous Ir-Cu nanocrystals with three-dimensional electrocatalytic surfaces. Chem. Mater. 2018, 30, 8571-8578. [CrossRef]

28. Wang, Q.; Ming, M.; Niu, S.; Zhang, Y.; Fan, G.Y.; Hu, J.S. Hydrogen evolution: Scalable solid-state synthesis of highly dispersed uncapped Metal ( $\mathrm{Rh}, \mathrm{Ru}, \mathrm{Ir})$ nanoparticles for efficient hydrogen evolution. Adv. Energy Mater. 2018, 8, 1801698. [CrossRef]

29. Wang, C.; Sui, Y.M.; Xiao, G.J.; Yang, X.Y.; Wei, Y.J.; Zou, G.T.; Zou, B. Synthesis of Cu-Ir nanocages with enhanced electrocatalytic activity for the oxygen evolution reaction. J. Mater. Chem. A 2015, 3, 19669-19673. [CrossRef]

30. Zeng, H.B.; Du, X.W.; Singh, S.C.; Kulinich, S.A.; Yang, S.K.; He, J.P.; Cai, W.P. Nanomaterials via laser ablation/ irradiation in liquid: A review. Adv. Funct. Mater. 2012, 22, 1333-1353. [CrossRef]

31. Amans, D.; Cai, W.; Barcikowski, S. Status and demand of research to bring laser generation of nanoparticles in liquids to maturity. Appl. Surf. Sci. 2019, 488, 445-454. [CrossRef]

32. Gavrilenko, E.A.; Goncharova, D.A.; Lapin, I.N.; Nemoykina, A.L.; Svetlichnyi, V.A.; Aljulaih, A.A.; Mintcheva, N.; Kulinich, S.A. Comparative study of physicochemical and antibacterial properties of ZnO nanoparticles prepared by laser ablation of $\mathrm{Zn}$ target in water and air. Materials 2019, 12, 186. [CrossRef] [PubMed]

33. Li, S.; Shao, Y.L.; Cui, L.; Kulinich, S.A.; Du, X.W. Spheroidization of nickel powder and coating with carbon layer through laser heating. Materials 2018, 11, 1641. [CrossRef] [PubMed]

34. Mintcheva, N.; Aljulaih, A.A.; Bito, S.; Honda, M.; Kondo, T.; Iwamori, S.; Kulinich, S.A. Nanomaterials produced by laser beam ablating Sn-Zn alloy in water. J. Alloys Compd. 2018, 747, $166-175$. [CrossRef]

35. Mintcheva, N.; Aljulaih, A.A.; Wunderlich, W.; Kulinich, S.A.; Iwamori, S. Laser-ablated ZnO nanoparticles and their photocatalytic activity towards organic pollutants. Materials 2018, 11, 1127. [CrossRef] [PubMed]

36. Kondo, T.; Sato, Y.; Kinoshita, M.; Shankar, P.; Mintcheva, N.N.; Honda, M.; Iwamori, S.; Kulinich, S.A. Room temperature ethanol sensor based on $\mathrm{ZnO}$ prepared via laser ablation in water. Jpn. J. Appl. Phys. 2017, 56, 080304. [CrossRef]

37. Honda, M.; Goto, T.; Owashi, T.; Rozhin, A.G.; Yamaguchi, S.; Ito, T.; Kulinich, S.A. ZnO nanorods prepared via ablation of $\mathrm{Zn}$ with millisecond laser in liquid media. Phys. Chem. Chem. Phys. 2016, 18, 23628-23637. [CrossRef] [PubMed]

38. Kulinich, S.A.; Kondo, T.; Shimizu, Y.; Ito, T. Pressure effect on ZnO nanoparticles prepared via laser ablation in water. J. Appl. Phys. 2013, 113, 033509. [CrossRef]

39. Svetlichnyi, V.A.; Shabalina, A.V.; Lapin, I.N.; Goncharova, D.A.; Kharlamova, T.S.; Stadnichenko, A.I. Comparative study of magnetite nanoparticles obtained by pulsed laser ablation in water and air. Appl. Surf. Sci. 2019, 467-468, 402-410. [CrossRef]

40. Brandiele, R.; Amendola, V.; Guadagnini, A.; Rizzi, G.A.; Badocco, D.; Pastore, P.; Isse, A.A.; Durante, C.; Gennaro, A. Facile synthesis of Pd3Y alloy nanoparticles for electrocatalysis of the oxygen reduction reaction. Electrochim. Acta 2014, 320, 134563. [CrossRef]

41. Feng, Y.; Li, Z.; Liu, H.; Dong, C.K.; Wang, J.Q.; Kulinich, S.A.; Du, X.W. Laser-prepared CuZn alloy catalyst for selective electrochemical reduction of $\mathrm{CO}_{2}$ to ethylene. Langmuir 2018, 34, 13544-13549. [CrossRef] [PubMed]

42. Reichenberger, S.; Marzun, G.; Muhler, M.; Barcikowski, S. Perspective of surfactant-free colloidal nanoparticles in heterogeneous catalysis. Chem CatChem 2019, 11, 1-31. [CrossRef]

(C) 2019 by the authors. Licensee MDPI, Basel, Switzerland. This article is an open access article distributed under the terms and conditions of the Creative Commons Attribution (CC BY) license (http://creativecommons.org/licenses/by/4.0/). 